\title{
Augmented Reality and Transversal System of Teaching-Learning to teach anatomy
}

\author{
Adalberto Bosco C. Pereira', Luan Felipe Cruz Alves', Igor Nascimento Guanais \\ Santos $^{1}$, Anne Eberhard ${ }^{2}$ \\ ${ }^{1}$ LPAI - University Center Senac - São Paulo -SP - Brazil \\ ${ }^{2}$ School of Medicine - Technical University of Munich - Munich - Germany. \\ adalberto.bcpereira@sp.senac.br, igorguanais@hotmail.com, \\ luanpsa2019@hotmail.com, annev.eberhard@gmail.com
}

\begin{abstract}
This paper deals with initial results by using Augmented Reality and Transversal System of Teaching-Learning (TSTL) to teach anatomy in an undergraduate course of Physical Education. The ongoing project aims to use existing and low-cost resources in lessons to promote accessibility and school inclusion. The resources needed for this research are smartphones in the perspective of BYOD (Bring Your Own Device) and VR cardboards as an optional feature to increase immersion. This research is qualitative, and its methodology is grounded in action-research. Analysis of data collected were based in the theory of Structural Cognitive Modifiability (SCM) of Reuven Feuerstein.
\end{abstract}

\section{Introduction}

Teaching and learning processes are interposed by different kinds of struggles and barriers. These obstacles vary according to didactic content, pedagogical proposal, the influence of the cultural and socioeconomic context of those involved - teachers or students, including the administration of the educational institution, its infrastructure and other processes of operation and management [Pereira 2017].

In Higher Education, students vary in relation to age, culture, and socioeconomic background. These variables create barriers to accessibility and appropriation of multimedia technological resources. As for institutions, there is also a need for a variety of resources available for teachers and students to use. For instance, teaching anatomy lacks the technological resources to explain the physiology and physiognomy of the human body in action. Therefore, AR could help to go over details that were not covered during the section. The fact that teaching anatomy depends on using real human organs in lessons is itself a complex barrier, and sometimes impossible to be overcome [Jamali et al, 2015; Karambakhsh et al. 2018].

The use of the Augmented Reality (AR) enables new ways of learning such as the possibility for students to see the world around them from different points of view, with the addition of realistic elements, filters, and academic information. The combination of virtual information with the real world enhances the connectivity of its elements since the use of smartphones is part of students' daily lives [Klopfer and Sheldon 2010].

Augmented Reality technology can, for example, project realistic images of parts of the human body, internal human organs, and skeletons in the real world. Interaction 
with these virtual objects is possible and it can also be used with pedagogical planning to facilitate the cognitive development of anatomy contents. Especially conveying structural details is often difficult to apply in cadaver sections due to time restrictions, which forces to focus on the practical side of the course. The possibility of collaborative interaction also allows many activities to be explored in the classroom, like a group discussion guided by a mediator about a virtual object in pedagogical contexts.

Dunleavy and Matt (2014) indicate two ways of AR use available to educators: 'location-based' and 'vision-based'. The former displays virtual information for students as they move through a physical area with a GPS sensor in a mobile device. The media in the mobile devices (text, graphics, audio, video, 3D models) augments the physical environment with narratives, navigation, and/or academic information relevant to the student. The latter presents digital media to students after they point the camera of their mobile device to an object such as: QR code, 2D image, or a flat area.

Given these challenges, the present research wants to contribute to the discussion of better ways of teaching and learning. Based on literature review, diagnostic evaluation of the students and teachers were drawn up the following research question: How the AR and TSTL combined can help anatomy teaching and learning? That lead us to the following hypothesis: the use of augmented reality resources in addition to an appropriate pedagogical strategy enables cognitive development, broadens possibilities for interaction, and motivates dialogic interaction in the classroom. This paper deals with a trans, inter and multidisciplinary research that has as object of study the paradigm of augmented reality for anatomy teaching.

\section{Literature Review}

Some systematic reviews about the use of AR in education were found [Dunleavy and Matt 2014; Chen et al. 2017]. Both focus on the use of augmented reality on mobile devices such as tablets and smartphones as these devices enable interaction of embedded digital information in the real physical world.

As examined by Dunleavy and Matt's (2014) the most frequently reported availability of $\mathrm{AR}$ is to present multiple but complementary perspectives on a problem located within a space. This characteristic is a direct result of the 1 to 1 ratio of device to student provided in most AR learning environments, where each student is interacting with a mobile device with a GPS sensor. This unique capacity allows educators to incorporate collaborative teaching techniques and experience activities based on questions that require critical thinking.

AR provides educators with the ability to leverage physical space as an additional layer of content for students to observe, manipulate, and analyze the content they are studying. However, it is necessary to embody these multiple perspectives into the environment and contextualize them within a problem-based narrative [Perry et al. 2008; Squire et al. 2007]. In other words, increasing the physical environment with digital information turns this environment into a place for multiple learning opportunities.

\section{Theoretical-Interpretative View}

This project treats education using digital technologies as a social phenomenon and, for this reason, adopts the action research methodology. This methodology deeply considers 
numerous features about social, economic, and cultural issues of the research object [Barbier 2007].

Unlike quantitative research, that seeks to compare intervention $\mathrm{X}$ to $\mathrm{Y}$ to measure $\mathrm{Z}$, this qualitative work wants to understand the use of AR in anatomy teaching and learning as a social phenomenon [Tenenberg 2019]. To accomplish that is indispensable to use a strong theoretical basis for education research.

Theory of Structural Cognitive Modifiability (SCM) and Mediated Learning Experience (MLE) of Feuerstein et al. (2014) were used for organizing the research tasks and data analysis in this study. This theory addresses the individual's modification, emphasizing autonomous and self-regulated changes. For Feuerstein, in addition to the stimulus exposures, the presence of a mediator is necessary to provoke cognitive alterations. This approach is like the cultural interactionist studies developed by Vygotsky (1984). MLE needs to have these three following essential characteristics: intentionality and reciprocity; transcendence; mediation of meaning. There is other important parameters for MLE to enable the diversity of human learning and development: feelings of competence; sharing behavior; individualization and psychological differentiation; regulation and control of behavior; goal seeking, goal setting, and goal achieving; search for challenge, novelty, and complexity; awareness of being a modifiable entity; optimistic alternatives; sense of belonging. These parameters of MLE derive from specific situations in the cultures that the teacher and the student belong to [Feuerstein et al. 2014].

Feuerstein echoes Vygotsky when he states that to fully understand the nature of human development, it is necessary to understand the interactions between the human being, the environment and the socio-cultural experiences, putting the student in direct interactions and mediated by other person [Feuerstein 1980; Feuerstein et al. 2014; Vygotsky 1984].

Activities that contain ludic situations enable the student's cognitive development, resulting in the orientation of the student's behavior through the immediate perception of the objects involved. In this study, AR provided a transient stage of perception, increasing its cognitive structures and world perception of the situation and the meaning attributed to it, and the action and interaction with virtual objects. This is similar to the concept of zone of proximal development (ZPD) [Vygotsky 1984], mediation and the mediator cause different cognitive changes to new constructions, favored by activities that include activity with augmented reality.

The transversal system of teaching-learning (TSTL) was used to plan the trial class: a) idealization and development of the pedagogical resource characterized as a mobile application of augmented reality; b) teacher script for its use in the classroom. TSTL provides explicit pedagogical basis in all educational processes from planning, design, implementation, execution, and evaluation, to the training and continuous improvement of teachers. It also covers the production of didactic material. TSTL has more than three decades of maturity based on research and practice with proven effectiveness [Filatro 2008; Piconez 2004].

Following the action-research steps, interviews with the anatomy teacher were carried out, followed by a diagnostic survey of the students through individual questionnaires made via Google Forms application. 
The setting is an University Center. The subject chosen is Anatomy from the Undergraduate Physical Education course. There were 48 students chosen to be part of the trial class supported by the AR application prototype. Participants were between the ages of 18 and $56 ; 27.1 \%$ female students; $47 \%$ had already used an educational application; only $18.8 \%$ had had some kind of contact with augmented reality application; $22.9 \%$ had used virtual reality application; $8.3 \%$ used an augmented reality application for educational purposes; $95.8 \%$ of the class had Smartphone, $23.9 \%$ of these with iOS system (Apple) and the remaining 76.1\% Android (Google).

These data were fundamental for the mapping challenges faced in the classes beyond the limitations of technological and multimedia resources available and used in the classroom. Based on the information provided by the teachers and diagnostic survey, it was possible to elaborate the following hypothesis: the use of augmented reality resources in addition to an appropriate pedagogical strategy enables cognitive development, broadens possibilities for interaction, and motivates dialogic interaction in the classroom. From this hypothesis the prototype and the pedagogical strategy of its use were developed to be performed in the classroom following the TSTL. The development of the application prototype was used the Unity Game Engine [Unity 2020] and its AR framework.

The application of the prototype in lessons adopted the following script:

- distribution of the material that includes the QRCode and cardboards in each table, such tables included groups of up to 6 students;

- beginning of the class with the presentation of the theme and script of the lesson; presentation of the Focal question, "What causes a person to faint?";

- explanation of how to use the cardboard next to your smartphone;

- beginning of initial activity with 15 minutes of interaction with the 3D heart;

- exposition of conceptual class;

- activity with 3D heart;

- activity evaluation;

- revision of focal question "What causes a person faint?".

The prototype evaluation consisted of the data collection via focus groups with students. It was done after the lesson where the AR application is used. In addition to the focus groups, data are also recorded in the field diary. The anatomy teacher is also interviewed and made his notes. At the time of the lesson, 3 teachers from other courses observed the experience and discussed their perception notes on the use of augmented reality. All these data were triangulated for a closer approximation of reality [Bonfim 2009; Victoria 2000; Cohen et al. 2002]. The second cycle of action-research of this approach was performed to evaluate a second prototype version with a focal group composed by four students and one anatomy teacher.

\section{Presentation of AR Application}

To test the possibilities of AR application, two action-research cycles of TSTL and AR applications were designed. These cycles aimed to explore pedagogical possibilities like: 1) possibilities to interact with real objects in real life; 2) investigate the user experience by using Head Mounted Display (HMD); 3) the user experience by using AR handheld; 3) combine different medias (book, x-rays, etc.) with AR content; 4) interact with professor, teach or other students when exploring AR content. 
The prototype was designed to be used by students and a teacher who may mediate the use of the application (Figure 1) as a way of favoring cognitive development, expanding possibilities for interaction, and motivating interaction, and dialog in lessons.

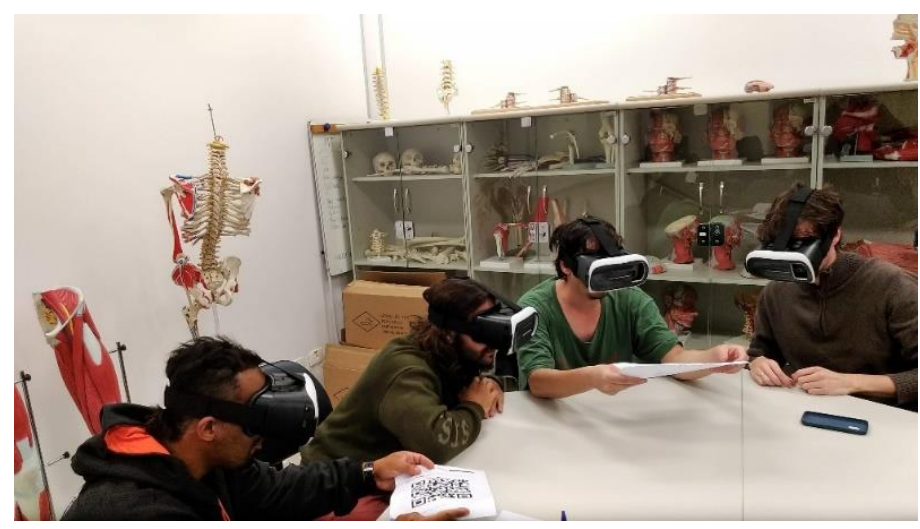

Figure 1. Application of the prototype in the anatomy class.

Figures 2 and 3 illustrate the application view when a QR code is positioned. In the case of Figure 2, a closed heart in 3 dimensions, separated in 2 screens, is observed. When placed on the cardboard, it causes the stereoscopic effect and increases the immersion.

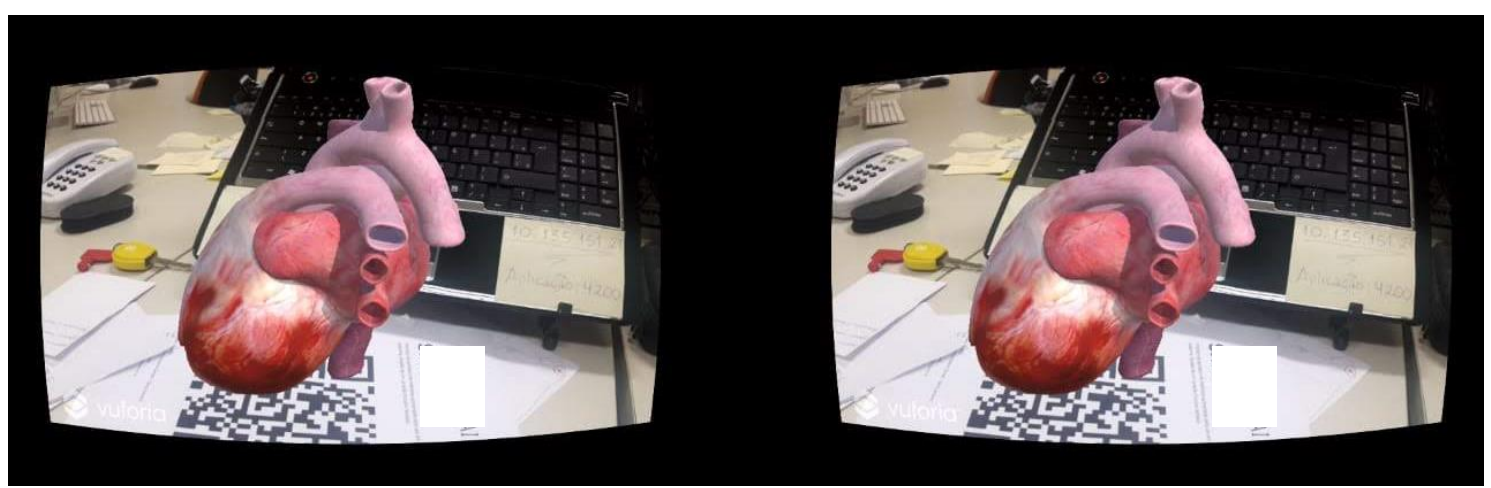

Figure 2. Stereoscopic view of the application.

In Figure 3 a) it is possible to observe another 3D model of the sliced heart that allows interaction with the interior of the heart. The two illustrated 3D models are realistically animated representing the living and beating human heart. Students here have a unique opportunity to experience something that is very difficult to reproduce: a moving human heart. Even with a real heart it would not be possible to experience something like this without the AR. In that app version the user needs to point the device's camera towards a QR code, as an anchor, to see the 3D AR content. Each QR code represent a different 3D object. The user can interact with the real object, in that case the printed QR code. The interaction can be rotate the QR code to rotate the $3 \mathrm{D}$ AR object or change scale by getting closer or move away. 


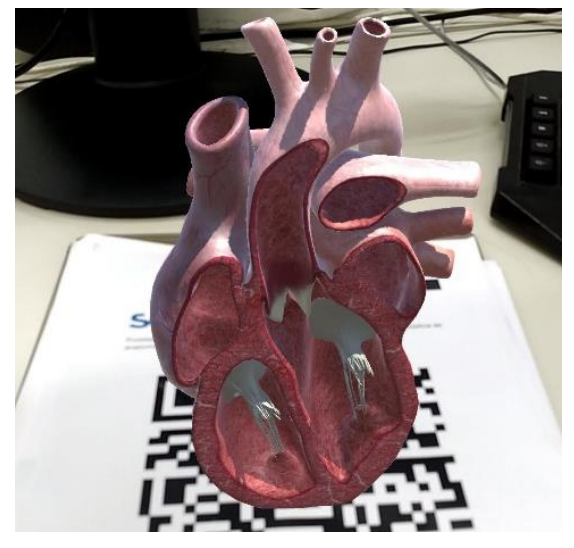

Figure 3. a) View of a sliced heart in AR.

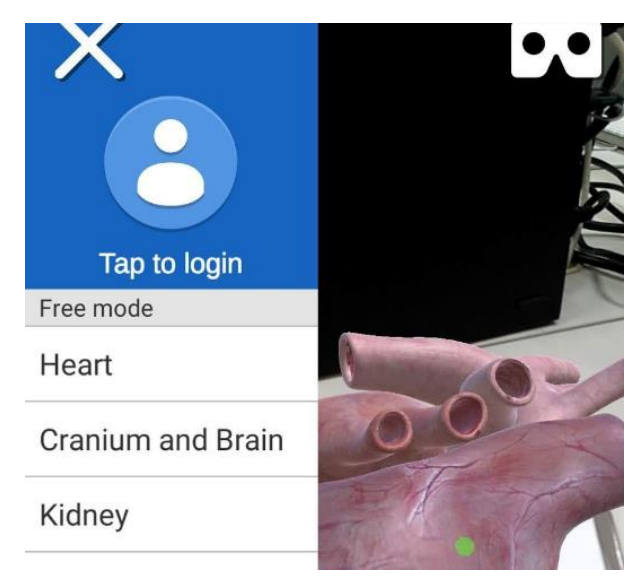

b) App menu.

The app is available only on Google Play for mobile devices equipped with Android 4.0+ operating system and can be found by the name "AnatomyLabAR". To view the $3 \mathrm{D}$ images, it is necessary to point the camera of the mobile device to $\mathrm{QR}$ codes.

The second cycle of action research have had a new app version redesigned based on feedback of surveys, interviews, and focal groups' action-research cycle. The main modification was that instead one QR code for each 3D model, the user needs to choose in the app menu which object will appear when pointing to the QR code. Other significant modifications: 1) Handheld mode; 2) New 3D model dataset: skull and brain, skeleton, kidney, lungs, arm muscle, back muscle, leg muscle, complete skull, digestive system and circulatory system; 3) Interactive menu (see figure $3 \mathrm{~b}$ )); 4) Online mode; 5) Pointer dot for online mode; 6) 3D object rotation and scale variation by touchscreen interaction; online mode the teacher can rotate and scale the 3D object of the students as well.

The 3D model dataset was bought at Unity Asset Store online [Unity 2020]. The user can control and setup the visual configuration at interactive menu (see figure $3 \mathrm{~b}$ )). The teacher can select what the students will see, point whit the green dot, rotate, and scale-up/down in online mode.

\section{Preliminary results}

Preliminary results are the outcomes data analysis from: the diagnostic survey, the field diary, the discussion of researchers, the teachers' (Teacher $1 \mathrm{~T} 1$ and T2) interviews, the focus groups, which showed the problems and barriers of anatomy teaching, and triangulation.

Both teachers claim students have problems in representing physical and physiological phenomena in the anatomy classes, as some of these phenomena require observation and interaction in three dimensions. These phenomena require massive effort from the teacher to deliver the proposed content, demanding a previous pedagogical planning, when represented in paper, blackboard, or projector. Problems reported by teachers are: 1) examining the functioning of human organs; 2) having a realistic visualization in 2D media; 3) creating relations of theoretical content with reality; 4) dealing with the limitation of interaction in 2D media.

After the trial lesson using augmented reality and TSTL, one of the teachers made several notes. One of them argued the use of augmented reality and the interaction with a 
three-dimensional (3D) heart enabled deeper discussions about what students have been able to visualize.

That same teacher realized that the strategy and the planning of the lesson, with a previous TSTL script was crucial to the success of lessons. This was because using a new and different technology takes time, considering the activity planned were to last 15 minutes and ended up lasting one hour, due to the fact students have had some problems like inserting their smartphones in the cardboards.

The T1 revealed the Transversal System of Teaching-Learning was beneficial and its application made the classroom practice dynamic and interesting, keeping the students immersed in the activities and expository lessons. Another important observation was that the interaction with the 3D heart before the expository lesson enabled the understanding of concepts, as students had previously interacted with the phenomena and physiology of the human heart. According to the Teacher 1 it resulted in saving time in exposing concepts in lessons. At the beginning of the lesson's students were unable to answer the focal question. However, when the teacher established a relationship between the focal question, the content of lessons and the sports their usually practice, the importance and meaning of the content made sense to the students.

The focus group were applied with students after a lesson using AR content. The goal was to discuss the experience with AR content in educational context. The main questions asked in focal group were: 1) Name up to three difficulties that you faced while using the smartphone AR app; 2) From your point of view elaborate up to three benefits of smartphone AR app; 3) Name up to three improvements you would like to make to the AR app.

The results from the students' point of view revealed that there were some problems during classes, such as the cardboard manipulation, the heating up of smartphones, the fast battery draining. One of the students reported having back head pain, dizziness, and pain behind the eyes.

On the other hand, some advantages were addressed. The students described that the interaction with the 3D heart helped in the understanding of the physiology and the physiognomy of the heart both internally and externally, resulting in an effective knowledge construction. They claimed that technology enables a calm environment to learn, not mentioning its practicality. One of the groups of students stated: "It approximates the learning closer to real situations because the observation is in $3 \mathrm{D}$, much superior to the visualization when compared to the books" and "the traditional classroom dynamics without technological resources is stressful. Changing the class dynamics by adding new media is unwinding". Students also have given some suggestions for improvements to the application, such as adding audio, adding information within the AR interaction, and improving interactivity.

For the researchers, it is possible to notice that students were very excited and motivated with the new technology. Some students have complained about the demands of the application because of the computational processing, which led to smartphone heating up. The teacher who taught the class mentioned that the TSTL dynamics of the lessons were very interesting, different from what he was used to. He also noticed that the students were more attentive, being more engaged in the challenges regarding the focal question. With the teacher's help the students were able to overcome the challenge of answering the focal question. T1 claimed that AR helps skip stages in the teaching 
processes, and this became clear when the teacher took advantage of $3 \mathrm{D}$ animation to explain the physiology of the functioning heart.

The second cycle of action research used that previous feedback to redesign the AnatomyLabAr application with new features and modifications, already described at section 4, to fit better the teacher and students' experience (see fig. $3 \mathrm{~b}$ )). A focal group was performed with four students and one teacher. This focal group revealed that the improvement significantly increased the user experience. Regard the cardboard usage to increase the immersion it was consensus the preference to use by handheld mode. Suggestions of 3D interaction by touch screen commands for rotate and scale change was proposed in this focal group.

These findings validate that the AR combined with proper pedagogical strategies TSTL can be used as an MLE to favors the mediation of meaning and intentionality, reciprocity, regulation and control of behavior, student's transcendence, sharing behavior, and optimistic alternatives.

\section{Discussions}

The benefits of interaction with AR content involves using real-world cues and spatial relationships based upon the user's position in the environment. This creates a facilitation to learning and teaching process [Breakey et. al. 2008; Samosky et al. 2012; González et. al. 2019]. Our results reinforce that, and other important point is the interaction between students and teachers or professors during the lessons with AR content allow new ways of learning and teaching.

Kangdon Lee (2012) highlights issues, problems, and barriers about AR adoption in training and educational processes. Another essential highlight is the importance to combine AR content with proper learning methodologies. Another point of view is that AR brings different perspectives to students and teachers, which can be turned in different discussions facilitating knowledge construction.

AR is aligned with constructivist theories of teaching and learning where students take control of their own learning, improving their autonomy and could provide education opportunities more meaningful [Lee 2012; Vygotsky 1984; Feuerstein et. al.2014]. The AR education experiences guided by teachers and professors favor the use of previous knowledge leading to successful actions and avoid mistakes. For that it is important to consider training for teachers and professors for correctly use of any kind of technology, and pedagogical strategy in lessons.

These findings support that smartphones can be an important ally to AR content consumption popularization. Low cost alternatives for AR content can promote its consumption culture. The fact of smartphones is already part of contemporary people daylife, using it to a complex experience like AR content for education become more affordable.

\section{Final considerations}

The project is in its initial phase and the application is still in its prototype version. However, the pedagogical possibilities of assisting the teacher in the classroom, offering meaning and sense, in addition to enabling teachers to skip stages in the teaching and content transfer processes have already become evident. As work in progress, there is 
need keep the investigation for more findings about the students learning by using TSTL and AR content. Despite the need for validation of the prototype, the triangulation of the results shown suggested that, there are improvements and modifications proposed by the students and teachers that need to be analyzed in depth by the development team in order to create a new prototype that can be validated. This result is important to reinforce the need to plan lessons and activities considering the use of digital media.

Technology has been carefully used based on a plan to avoid any kind of harm in class. There are still some technical and content adjustments in the application to improve its efficiency. The application itself was good for students to notice a new point of view, in a new media, the content of the lesson, but alone it does not help and can disrupt the classroom routine. The fact that the lesson was planned together with the focal question contributed to for the subject to be meaningful for the students.

The hypothesis "the use of augmented reality resources in addition to an appropriate pedagogical strategy enables cognitive development, broadens possibilities for interaction, and motivates dialogic interaction in the classroom" was proved in this specific context. However, with the condition that it is necessary planning and using pedagogical strategies consistently with its implementation. The project is still in progress and will use these results to refine the prototype and collect more data in the future.

\section{References}

Barbier, R. (2007). A pesquisa-ação. In A pesquisa-ação.

Breakey, K. M., Levin, D., Miller, I., \& Hentges, K. E. (2008). The use of scenario-basedlearning interactive software to create custom virtual laboratory scenarios for teaching genetics. Genetics, 179(3), 1151-1155.

Chen, P., Liu, X., Cheng, W., \& Huang, R. (2017). A review of using Augmented Reality in Education from 2011 to 2016. In Innovations in Smart Learning. Springer, Singapore. 13-18.

Cohen, L., Manion, L., \& Morrison, K. (2002). Research methods in education. routledge.

Dunleavy, Matt; Dede, Chris. Augmented reality teaching and learning. In: Handbook of research on educational communications and technology. Springer, New York, NY, 2014. p. 735-745.

Feuerstein, R. (1980). Instrumental enrichment: An intervention program for cognitive modifiability. Univ Park Pr.

Feuerstein, R., Feuerstein, R. S., \& Falik, L. H. (2014). Além da inteligência: aprendizagem mediada e a capacidade de mudança do cérebro. Petrópolis: Vozes.

Filatro, A. C. (2008). Learning design como fundamentação teórico-prática para o design instrucional contextualizado. Tese de Doutorado, Faculdade de Educação, Universidade de São Paulo, São Paulo.

González, A. V., Koh, S., Kapalo, K., Sottilare, R., Garrity, P., Billinghurst, M., \& LaViola, J. (2019, October). A comparison of desktop and augmented reality scenario based training authoring tools. In 2019 IEEE International Symposium on Mixed and Augmented Reality (ISMAR) (pp. 339-350). IEEE. 
Jamali, S. S., Shiratuddin, M. F., Wong, K. W., \& Oskam, C. L. (2015). Utilising mobileaugmented reality for learning human anatomy. Procedia-Social and Behavioral Sciences, 197, 659-668.

Karambakhsh, A., Kamel, A., Sheng, B., Li, P., Yang, P., \& Feng, D. D. (2018). Deep gesture interaction for augmented anatomy learning. International Journal of Information Management.

Klopfer, E., \& Sheldon, J. (2010). Augmenting your own reality: Student authoring of science-based augmented reality games. New Directions for Youth Development, 128 (Winter), 85-94.

Lee, K. (2012). Augmented reality in education and training. TechTrends, 56(2), 13-21.

Pereira, A. B. C. (2017). Uso de jogos digitais no desenvolvimento de competências curriculares da matemática.

Perry, J., Klopfer, E., Norton, M., Sutch, D., Sandford, R., \& Facer, K. (2008). AR gone wild: two approaches to using augmented reality learning games in zoos. Proceedings of the 8th international conference on International conference for the learning sciences, The Netherlands, 322-329.

Piconez, S. C. B. (2004). Sistema Transversal de Ensino--Aprendizagem: do referencial teórico à prática político-pedagógica na sistemática de planejamento para educação básica. Cadernos Pedagógicos Reflexões, 1(4).

Samosky, J. T., Nelson, D. A., Wang, B., Bregman, R., Hosmer, A., Mikulis, B., \& Weaver, R. (2012, February). BodyExplorerAR: enhancing a mannequin medical simulator with sensing and projective augmented reality for exploring dynamic anatomy and physiology. In Proceedings of the Sixth International Conference on Tangible, Embedded and Embodied Interaction (pp. 263-270).

Squire, K., \& Jan, M. (2007). Mad city mystery: Developing scientific argumentation skills with a place-based augmented reality game on handheld computers. Journal of Science Education and Technology, 16 (1), 5-29

Tenenberg, Josh. (2019). Qualitative methods for computing education. The Cambridge handbook of computing education research, p. 173-207.

Unity. (2020). Disponível em: < https://unity.com/pt>. Acesso em: 09, junho de 2019.

Vygotsky, L. S. (1984). The social formation of mind. 